This item was submitted to Loughborough's Research Repository by the author.

Items in Figshare are protected by copyright, with all rights reserved, unless otherwise indicated.

\title{
Computational modelling of mechanical behavior of biological tissues for biomedical applications
}

PLEASE CITE THE PUBLISHED VERSION

http://www.eccomas.org/cvdata/cntr1/spc7/dtos/img/mdia/eccomas-2016-vol-1.pdf

\section{PUBLISHER}

European Community on Computational Methods in Applied Sciences (ECCOMAS)

VERSION

NA (Not Applicable or Unknown)

\section{PUBLISHER STATEMENT}

This work is made available according to the conditions of the Creative Commons Attribution-NonCommercialNoDerivatives 4.0 International (CC BY-NC-ND 4.0) licence. Full details of this licence are available at: https://creativecommons.org/licenses/by-nc-nd/4.0/

\section{LICENCE}

CC BY-NC-ND 4.0

\section{REPOSITORY RECORD}

Li, Simin, Yang Liu, Juan Du, Begum Zeybek, Lorenzo Zani, Mark P. Lewis, and Vadim V. Silberschmidt. 2019. "Computational Modelling of Mechanical Behavior of Biological Tissues for Biomedical Applications". figshare. https://hdl.handle.net/2134/25083. 


\title{
COMPUTATIONAL MODELLING OF MECHANICAL BEHAVIOR OF BIOLOGICAL TISSUES FOR BIOMEDICAL APPLICATIONS
}

\author{
Simin Li ${ }^{1}$, Yang Liu ${ }^{1}$, Juan Du ${ }^{1}$, Begum Zeybek ${ }^{1}$, Lorenzo Zani ${ }^{1}$, Mark P. Lewis ${ }^{2}$ and \\ Vadim V. Silberschmidt ${ }^{1}$ * \\ ${ }^{1}$ Wolfson School of Mechanical and Manufacturing Engineering \\ ${ }^{2}$ School of Sport, Exercise and Health Sciences \\ Loughborough University, UK \\ E-mail: V.Silberschmidt@lboro.ac.uk
}

Keywords: Computational Modelling, Tissues, Biomedical Applications

\begin{abstract}
Computational modelling of biomedical applications has gained significant momentum in recent years, in part to meet demands related to recent technical advancements in manufacturing of personalized biomedical equipment. However, our understanding of mechanics of biological tissues, their properties and performance as well as their interaction with biomedical equipment still remains limited. This is a result of multiple factors, most important being a hierarchical and heterogeneous nature of biological tissues, non-trivial loading and environmental conditions to which they are exposed as well as multi-disciplinary nature of the systems involved.
\end{abstract}

This paper presents an overview of the latest research activities and achievements in the area of mechanics of biomaterials and tissues at Loughborough University, UK. It covers various types of biological materials and tissues - both hard (bones) and soft (muscles, etc.) - that have been studied in previous studies [1-4] at various spatial and temporal domains. These studies laid a foundation for development and implementation of advanced computational modelling of mechanics of these biological tissues at different stages (healthy, diseased and traumatic conditions) and for several areas of biomedical applications (injury prevention, wound care and rehabilitation). Performed numerical simulations, on the one hand, elucidate processes of deformation of biological tissues and, on the other hand, provide solutions for design and optimization of medical and rehabilitation procedures and devices. This work underpins a unique partnership between engineers, clinics and rehabilitation centres in UK aiming to transfer the latest scientific and technological advancements into personalized biomedical applications using computational schemes and tools. 


\section{INTRODUCTION}

Every year approximately 6,000 major limb amputations are performed in England according to the National Health System [5]. The clinical practice after an amputation involves a long period of physiotherapy and rehabilitation that requires the use of prosthesis. The main function of prosthesis for amputee is to substitute a missing part of the body with an artificial device that restores structure and functionality to the maimed musculoskeletal system caused by a limb loss.

During the initial rehabilitation stage, routine wound-healing techniques are usually incapable of achieving complete wound closure. Therefore, advanced wound-care methods are applied. The care of complex wounds is one of the most significant challenges for healthcare systems today. In an ideal scenario, residual extremity is covered with well-vascularized muscles, fascia and skin. However, in the case of traumatic amputation, the remaining skin structure is not always sufficient to fully cover the operation area, and it is therefore difficult to dress the wounded area [6-9]. To overcome this problem, a negative-pressure wound therapy (NPWT) is applied to (a) protect the open-wound area from infection instead of using conventional dressing and (b) promote the healing process [10].

NPWT has become a significant part of modern wound care and is used routinely in hospitals throughout the world. It involves controlled application of sub-atmospheric pressure to a wound bed through a wound filler (foam or gauze) placed in the wounded area [11]. The wound is then sealed with an adhesive drape that allows pressure to be applied and helps to provide a moist environment supporting the wound healing. The wound filler and drape protect the wound bed from bacteria and other contaminants and reduce a risk of friction or shear as well as other bodily fluids, enhancing the body's ability to heal [12]. Sub-atmospheric pressure removes an exudate and promotes healing in various ways.

After a successful wound healing, the next rehabilitation step for the amputee is to wear prosthesis. A typical lower-limb prosthesis is composed by four principal components: a socket, a suspension mechanism, a pylon providing the anchor point for a prosthetic foot. The socket is the most important factor for a successful prosthesis design because it acts as an interface between the residual and the artificial limb. The main function of the socket is to transmit forces during the ambulation, assure prosthesis stability, hold and protect the residual limb. Currently, the socket design and manufacture still relies on an artisanal process, which is non-standard and non-repeatable resulting in non-predictable performance $[13,14]$. From a patient's point of view, the most important functionality of the socket is its usability, where a socket should provide the wearer at least the stability and comfort during day-to-day wearing.

Instead of using a socked-based prosthesis approach, another method to replace the limb loss could be the use of an osseointegrated implant [15]. A successful use of such an implant relies on structural integrity of tissues surrounding the bone, which is subjected to a continuous remodelling process [16]. The investigation of this process is important to predict and improve bone adaptation after amputation. Human bone, as one of the most functional tissues in the body, exhibits the ability of restructure itself in responding to mechanical as well as metabolic stimuli, adjusting its internal structure and external shape. Although numerous computational models have focused on a fracture healing process, few studies have investigated the bone-remodelling process after lower limb amputation. [16].

In the past decade computational modelling has become increasingly popular in the field of biomechanics thanks to exponentially growing computer power [17]. In order to reach the goal of an individualised model, a set of tools including medical imaging, image acquisition and processing, mesh generation, material modelling and finite-element simulation becomes a necessity. The field of biomechanics suffers from one very severe restriction: in general, it is 
not possible for ethical reasons to measure forces and pressure within the human body. Thus, a typical measurement technology in biomechanics works on the interface between a body and its environment. The only possible way to address this challenge is to develop realistic biomechanical models of the human body, which can adequately predict mechanical behaviours of the tissues [17]. For this purpose, the developed computational models are provided as a framework allowing an insight into the analysis of mechanical interaction between tissues, wounded area and biomedical devices.

The aim of this paper is to give a better understanding of healing, recovery and remodelling processes at various stages of rehabilitation period after a lower limb amputation.

\section{MATERIALS AND METHOD}

Three finite-element models were developed in order to observe (i) the effects of negative pressure healing therapy after trans-femoral amputation, (ii) pressure distribution acting on transtibial residuum during daily activities, and (iii) prediction of a bone-remodelling process that occurs after the transtibial amputation. For the purpose of creating more realistic geometry in the three models, CT-scan-based image data for human legs containing bones and soft issues (including skin, fat, muscle, tendon and ligament) were obtained. The acquired geometries were imported into ABAQUS 6.14 software for individual finite-element analysis of each model.

\subsection{Model of negative pressure wound therapy}

NPWT involves a controlled application of sub-atmospheric pressure to a wound bed through a wound filler (foam or gauze), placed in the wound. The developed model contains three main domains: a rigid bone structure, a soft tissue with a wounded area (12 mm in depth) located at the distal region of the residual limb and wound filler modelled as polyurethane foam. The soft tissue including muscles, fat and skin was modelled as a single bulk elastic material.

In a human anatomic structure, all layers appear more or less tied to their neighbours by network of infiltrating collagen fibres (although some can be identified more easily than others). Hence, epidermis, dermis, hypodermis, muscles, tendons and bones are all embedded in a same continuous collagenous network. Therefore, a tie constraint was defined between a lateral surface of the bone and muscles. However, a lower part of the bone was not tied to the muscle to present a result of the amputation process. Meanwhile, the filler and the soft tissue were tied to each other in order to obtain integrity between them during the negative pressure application. A drape on top of the filler is neglected to simplify the geometry.

A choice of the element type for finite-element meshing procedure depends on a type of analysis to be performed and an expected level of precision [18].Nodes of the model were arranged according with the most stressed regions expected. A 10-node quadratic tetrahedron (C3D10) element type was defined, as shown in Figure 1.

The model aims to simulate application of the negative pressure wound therapy in a transfemoral amputee. At this stage, a fluid removal process was neglected in order to create a more simple approach. Different negative pressure levels of $70 \mathrm{mmHg}, 110 \mathrm{mmHg}, 125$ $\mathrm{mmHg}$ and $150 \mathrm{mmHg}$ were applied within the wounded tissue area and the top of the filler.

\subsection{Model of pressure distribution in residuum}

The finite element model was composed by four parts: resected bones (tibia and fibula), soft tissue, liner and prosthetic socket. While the residuum geometry came from segmentation process, the prosthetic components were designed individually. The liner was modelled with a 
digital wrapping technique resulting in a constant wall thickness equal to $6 \mathrm{~mm}$ to simulate a market available product [Iceross Comfort - Össur's Reykjavik Iceland].
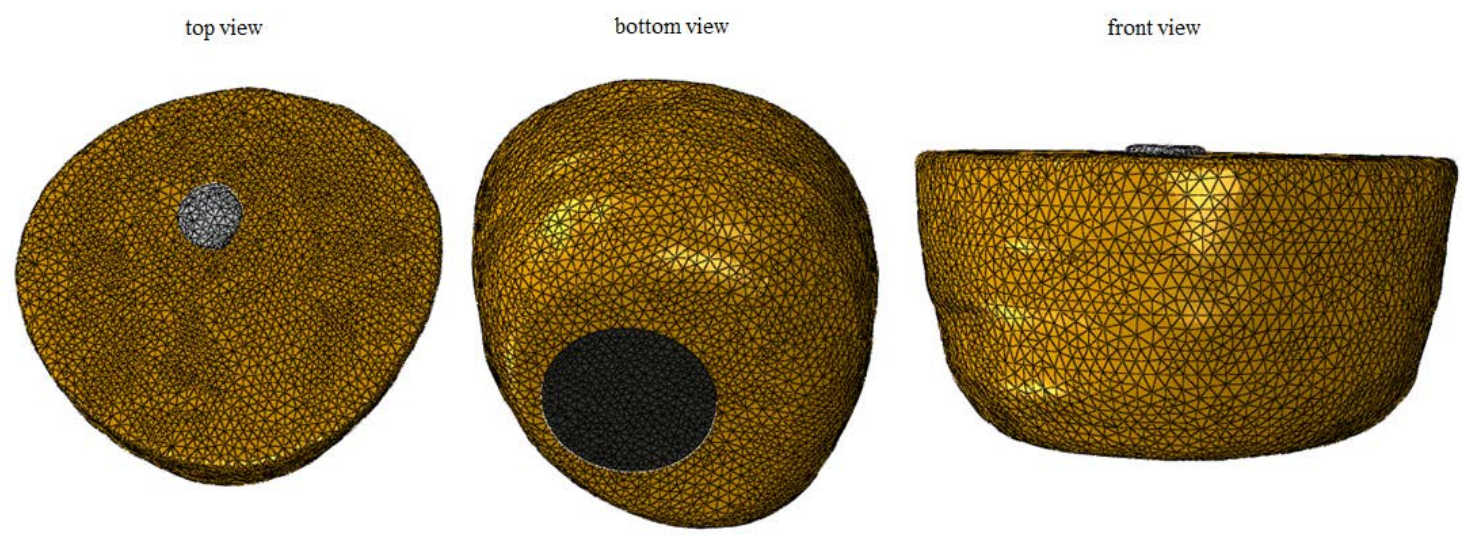

Figure 1: Top, bottom and front views of meshed geometry used in NPWT model

The same approach was followed in prosthetic socket modelling. The bottom end of the socket was combined with a disk having $50 \mathrm{~mm}$ height and $60 \mathrm{~mm}$ diameter aligned with tibial axis for socket/prosthetic limb adapter. Bones and socket parts were assumed to be linearelastic, homogeneous and isotropic having Young's moduli of 15GPa and 1.3GPa respectively and Poisson ratio of 0.3. Residuum soft tissues and liner materials used in the analysis were assumed to be hyper-elastic, homogeneous and isotropic. An Ogden's strain-energy-function model was applied to the soft tissues and the liner in order to model the nonlinear behaviour of isotropic rubber-like material behaviour [19].

Coefficients of the Ogden's model describing hyper-elastic mechanical behaviour of the soft tissues were evaluated by fitting the experimental stress-strain curve of passive muscle behaviour investigated by Calvo et al. [20]. The prosthetic liner was assumed made of silicon rubber according with the manufacturer's description. The Ogden's model was then applied fitting the stress-strain curve based on experimental data shown in Sanders et al. [21].

All the domains were free-meshed with 10-node quadratic tetrahedral elements type (C3D10). A pin encastre boundary condition ( $\mathrm{U} 1=\mathrm{U} 2=\mathrm{U} 3=0)$ was applied on the tibia plate, while a single vertical force equal to a half body weight $(370 \mathrm{~N}$ ) was applied on the lower surface of the socket/prosthetic limb adapter simulating a stance scenario. The main features of the model are graphically summarised in Figure 2.

\subsection{Model of bone-adaptation process}

A 2D finite-element model of a transtibial amputation was developed based on the geometry obtained from the CT scan. The bone-remodelling process was simulated caused by an osseointegrated prosthetic implant. There are three main components in the model: a corticalbone region modelled as elastic materials, an osseointegrated implant and a bone-remodelling region, which permits the adaptation of the materials as a result of mechanical loading (Figure 3 ). The shape and dimensions of the model were based on the cross-sectional area obtained from the previous model (see Section 2.2). An osseointegrated implant was fitted in a tibia's medullary cavity and modelled as analytical rigid body. The material properties of cortical bone such as its Young's modulus and Poisson's ratio were taken from the literature [22]. Both cortical- and virtual-bone domains were meshed with a CPS4R element type. 


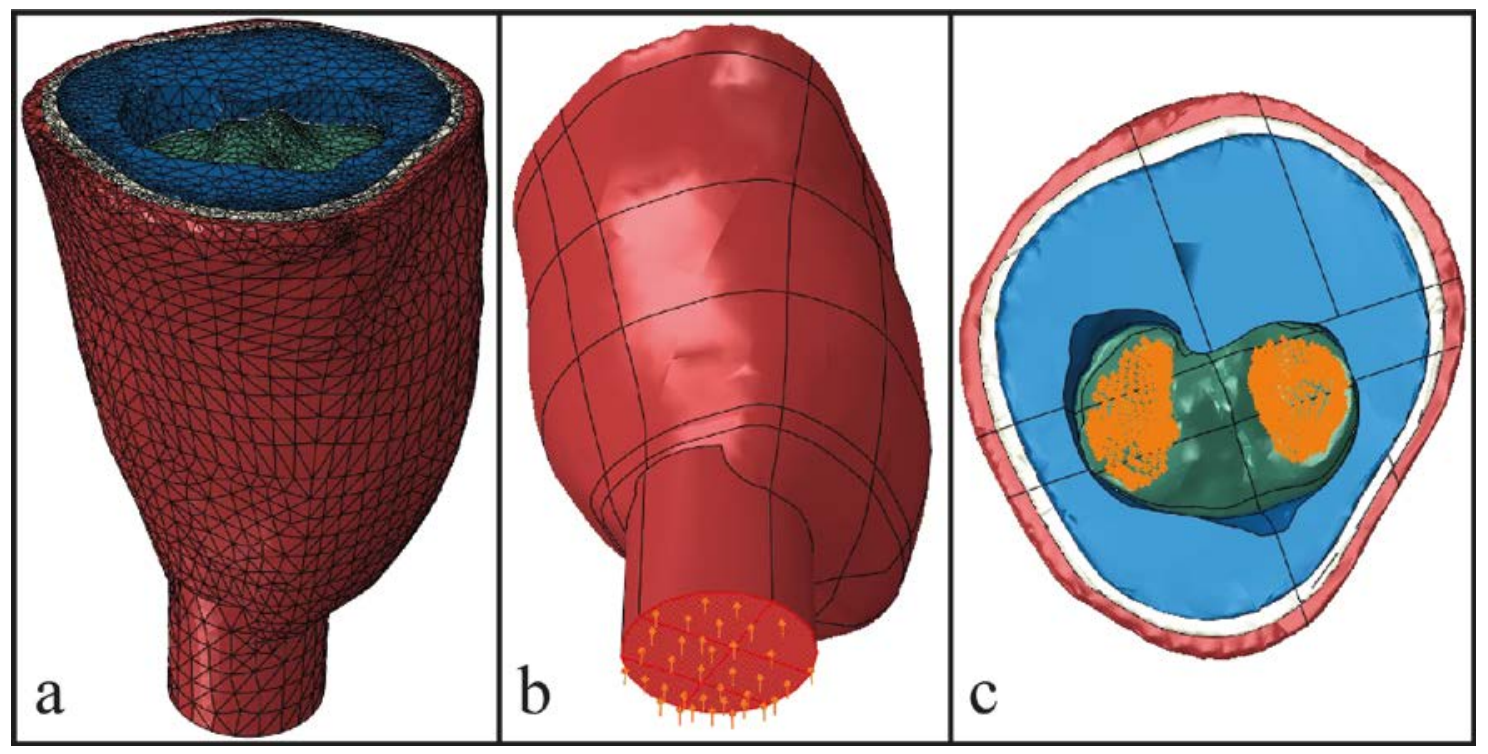

Figure 2: Finite-element model of transtibial limb and prosthesis:(a) model mesh; (b) loading condition; (c) boundary condition

In order to investigate the effect of different loading conditions on the process of bone remodelling related to osseointegration, three loading conditions were simulated: (a) a normal walking condition, with the load applied in both transverse and vertical directions; (b) a transverse loading condition, and (c) a transverse loading condition with $40 \%$ load reduction. The data were obtain from the work of Kutzner et al. [23]. 1/8 of the peak load was applied in the current model, in order to convert the force obtained from 3D to 2D model. The forces were applied on the bottom of the prosthesis. The tibia's top surface was fixed.

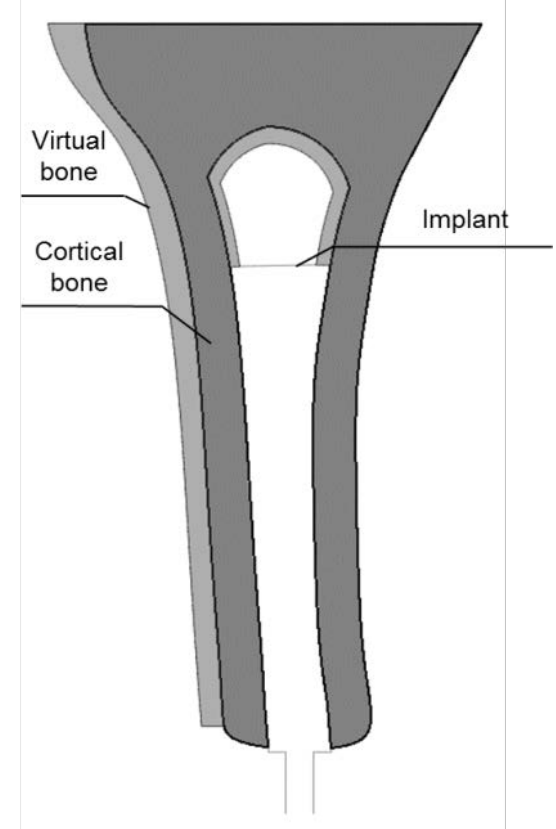

Figure 3: Two-dimensional FE model of transtibial osseointegration with implant and virtual bone-growth domain

In this study, a cubic relationship between the Young's modulus and bone density was in- 
troduced for the bone-remodelling region according to the theory of Carter and Hayes [24]. Furthermore, based on the remodelling theory of Weinans et al. [25], the density change in the bone tissue was in accordance with the strain-energy density. An ABAQUS user subroutine USDFLD was developed to implement the remodelling algorithm. After completing the boneadaptation algorithm, elements with zero density were removed from the region.

\section{RESULTS AND DISCUSSION}

In this section the results of three different models are presented and discussed separately.

\subsection{NPWT model}

The main goal of this model was to advance our understanding of the mechanical effects of NPWT on healing and investigate a soft-tissue response to these effects propagating thorough the wounded tissue during the therapeutic application. The obtained results indicated that an increasing magnitude of negative pressure in the therapy increased levels of stresses and deformations inside the muscle tissue. Figure 4 shows the computed stress distributions inside the tissue for a selected sagittal plane of the model. To facilitate visualization of the soft tissue area, the bone and the filler were removed from the graph. Maximum stresses were localised at the interface between the filler and the foam. Unsurprisingly, increasing the level of negative pressure had an increasing effect on the interface between the bottom part of the amputee's bone and the soft tissue. Maximum deformation occurred around the interface between the filler and the tissue (Fig. 5) and increasing negative-pressure levels caused higher deformation around the tissue-filler interface.

$-70 \mathrm{mmHg}$

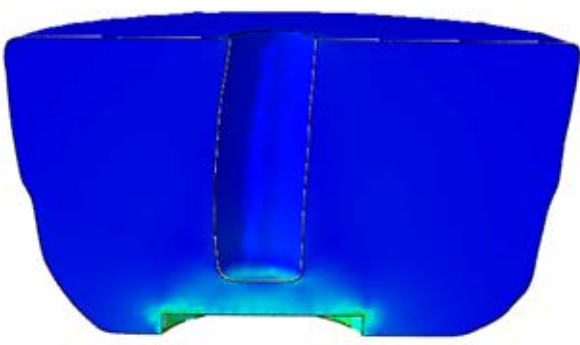

$-125 \mathrm{mmHg}$

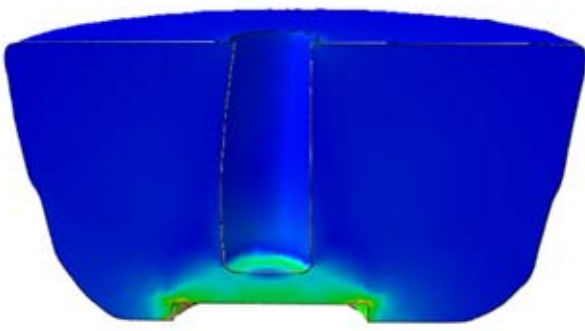

$-110 \mathrm{mmHg}$

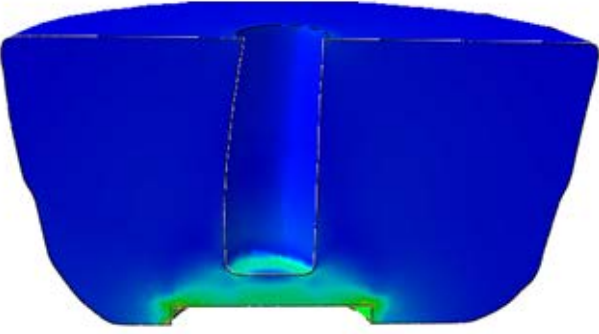

$-150 \mathrm{mmHg}$

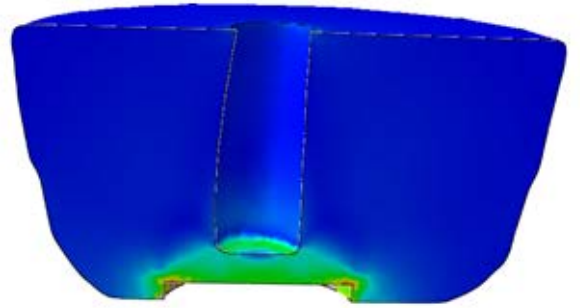

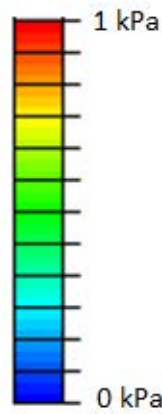

Figure 4: Comparison of distributions of von-Mises stress in sagittal plane of soft tissue for different levels of negative pressure 

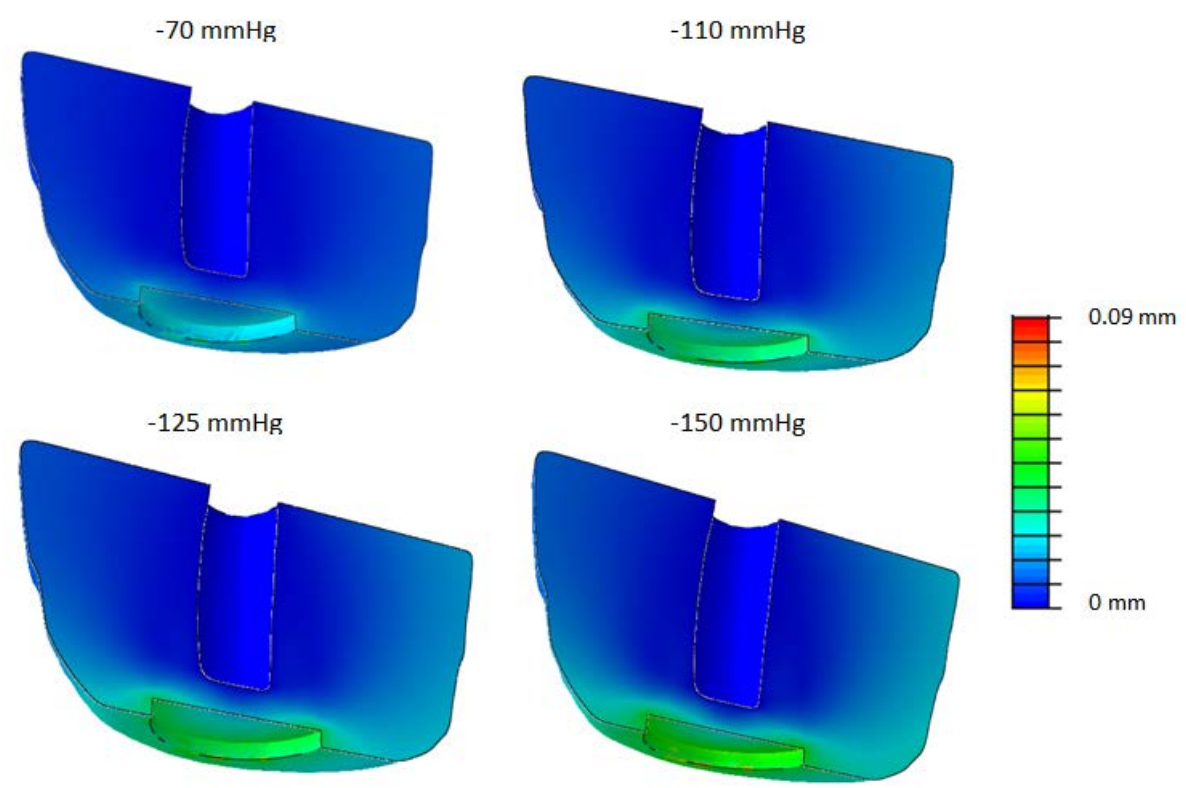

Figure 5: Comparison of deformations in sagittal plane of soft tissue for different levels of negative pressure

\subsection{Model of pressure distribution in residuum}

Numerical analysis of distribution of pressure (normal stress) was performed for the stump's internal soft tissue and at the interface between the residuum and the liner. A peak of pressure of $65 \mathrm{kPa}$ was found deep in the soft tissues surrounding the inferior-anterior part of the tibia bone (Figure 6a). On the interface between the residuum and the liner $50 \mathrm{kPa}$ maximum pressure was observed at the inferior-anterior part of the soft tissue (Figure 6b) as a result of the same loading condition. The results obtained are in agreement with a previous study [26] showing that stresses were concentrated in the flap tissue under the tibia's end and, therefore, a further study is needed on the clinical relevance in identifying risk factors of developing a deep-tissue injury (DTI) and other complications.

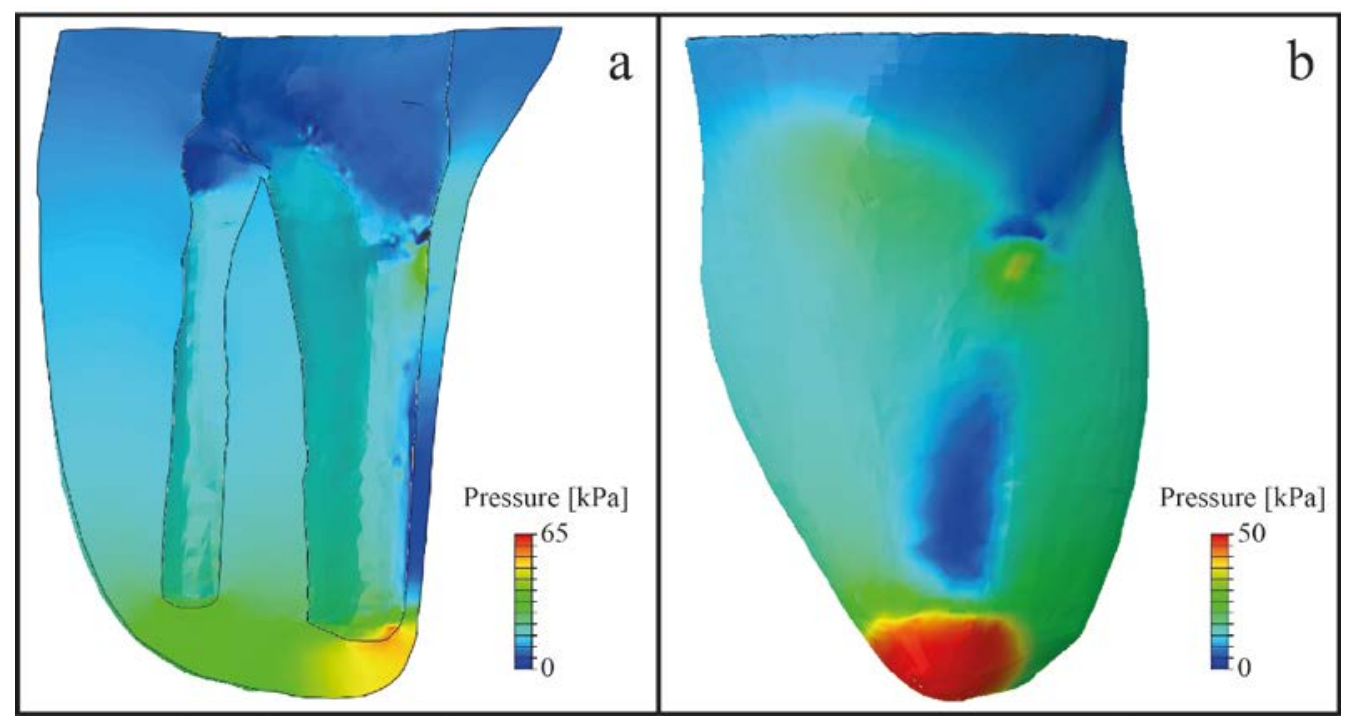

Figure 6: Pressure distribution in residuum: (a) cross-section view of residuum deep tissue; (b) anterior view of residuum-prosthesis interface. 


\subsection{Model of bone-adaptation process}

Three different shapes of bone-growth patterns were predicted for different loading conditions: normal walking, transverse loading and reduced transverse loading (by 40\%) (Figure 7). For the first conditions, the bone growth was predicted mostly for the top area of the left edge and the inner surface of the medullary cavity of the tibia. For the transverse loading condition, the bone growth on the left edge decreased significantly compared with the normal walking condition, with the shape of growth on the upper surface of the medullary cavity shifted as well. In case of reduced transverse loading, after the bone adaptation process, bone formed only at the top surface of the medullary cavity.

Strain-energy distributions for the normal walking condition before and after the remodelling process were also investigated in this study (Figure 8). The peak value of strain energy was $0.23 \mathrm{~mJ}$, located near the osseointegrated implant before the bone-remodelling process. After the process, the peak strain energy reduced to $0.11 \mathrm{~mJ}$. Comparison of strain energy before and after the remodelling process at the top corner of the medullary cavity demonstrted a reduction of strain energy from $0.187 \mathrm{~mJ}$ to $0.017 \mathrm{~mJ}$.

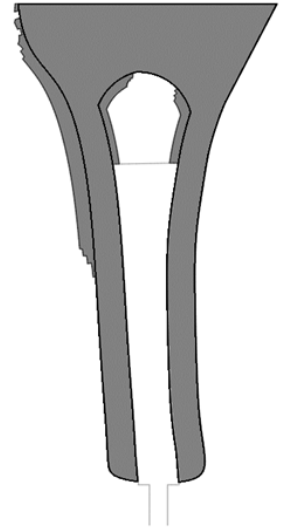

(a)

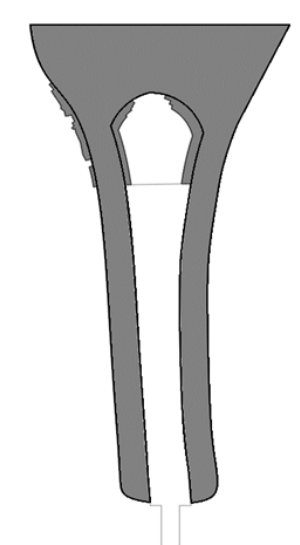

(b)

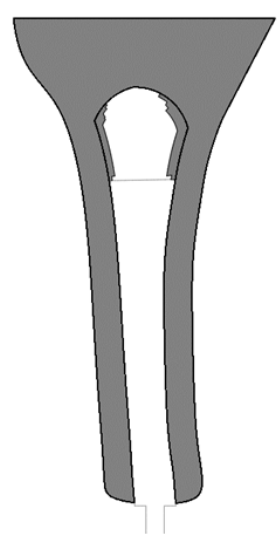

(c)

Figure 7: Predicted bone formation patterns for different loading conditions: (a) normal walking (load in both axial and transverse directions); (b) transverse loading; (c) reduced transverse loading

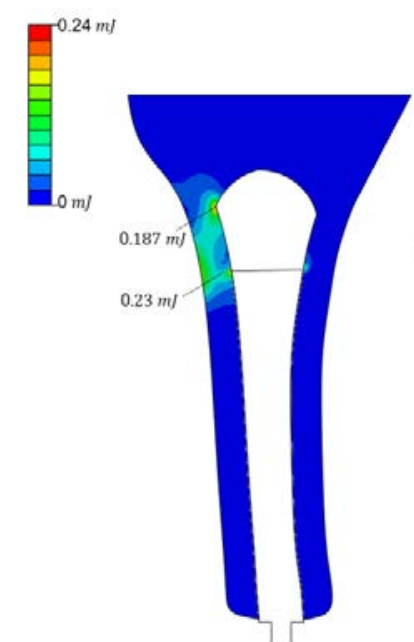

(a)

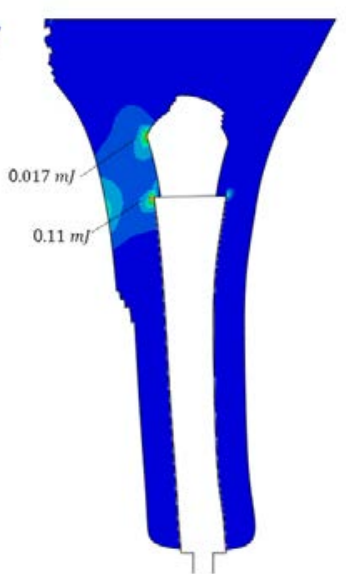

(b)

Figure 8: Strain-energy distribution for normal walking condition before (a) and after (b) remodelling process 


\section{CONCLUSIONS}

Three developed models provided initial understanding of biomechanical processes within the residual limb that is often not possible to achieve otherwise. The major advantage of this study is that advanced computational models provided intuitive interpretation of detailed mechanical behaviour of the biological tissues at various stages (healthy, diseased and traumatic conditions) and for several areas of biomedical applications (injury prevention, wound care and rehabilitation). With a repeated use of the model, various potential scenarios can be analysed, making it much easier to optimize the studied processes.

\section{REFERENCES}

[1] S. Li, E. Demirci, and V.V. Silberschmidt, "Variability and anisotropy of mechanical behaviour of cortical bone in tension and compression.” J. Mech. Behav. Biomed., vol. 21, pp.109-120, 2013.

[2] A.A. Abdel-Wahab, K Alam, VV Silberschmidt, "Analysis of anisotropic viscoelastoplastic properties of cortical bone tissues.” J. Mech. Behav. Biomed., vol. 4 no. 5, pp. 807-820, 2011.

[3] S. Li, A.A. Abdel-Wahab, V.V. Silberschmidt, "Analysis of fracture processes in cortical bone tissue.” Eng. Frac. Mech., vol. 110, pp. 448-458. 2012.

[4] S. Li, A.A. Abdel-Wahab, E. Demirci, V.V. Silberschmidt, "Penetration of cutting tool into cortical bone: Experimental and numerical investigation of anisotropic mechanical behaviour.” J. Biomech., vol. 47, no. 5, pp. 1117-1126, 2014.

[5] NHS. 2015. Amputation. [ONLINE] Available at: http://www.nhs.uk/conditions/ amputation/pages/introduction.aspx. [Accessed 15th March 2016]

[6] D. G. Armstrong and L. A. Lavery, "Negative pressure wound therapy after partial diabetic foot amputation: a multi-centre randomised controlled trial." Lancet (London, England), vol. 366, no. 9498, pp. 1704-10, 2005.

[7] D. Hinck, A. Franke, and F. Gatzka, "Use of vacuum-assisted closure negative pressure wound therapy in combat-related injuries--literature review.” Mil. Med., vol. 175, no. 3, pp. 173-181, 2010.

[8] K. Richter and B. Knudson, "Vacuum-Assisted Closure Therapy for a Complicated, Open, Above-the-Knee Amputation Wound.” J. Am. Osteopath. Assoc., vol. 113, no. 2, pp. 174-176, Feb. 2013.

[9] K. Couch and A. Stojadinovic, "Negative-pressure wound therapy in the military: Lessons learned.” Plast. Reconstr. Surg., vol. 127, pp. 117-130, 2011.

[10] V. Wong and S. Akaishi, "Pushing back: wound mechanotransduction in repair and regeneration.” J. Invest. Dermatol. vol. 131, pp. 2186-2196, 2011.

[11] E. Shweiki and K. E. Gallagher, "Negative pressure wound therapy in acute, contaminated wounds: documenting its safety and efficacy to support current global practice.” Int. Wound J., vol. 10, no. 1, pp. 13-43, 2013.

[12] S. Mendez-Eastman, "Guidelines for using negative pressure wound therapy." Adv. Skin Wound Care, vol. 14, no. 6, pp. 314-323, 2001.

[13] J. E. Sanders, E. L. Rogers, E. A. Sorenson, G. S. Lee, D. C. Abrahamson. "CAD/CAM trans-tibial prosthetic sockets from central fabrication facilities: how accurate are they?” J. Rehabil. Res. Dev. vol. 44, no. 3, pp. 395-405, 2007.

[14] J. E. Sanders, M. R. Severance, K. J. Allyn, "Computer-socket manufacturing error: how much before it is clinically apparent?” J. Rehabil. Res. Dev., vol. 49, no. 4, 
pp. 567-582, 2012.

[15] R. Brånemark, P. Brånemark, B. Rydevik, and R. R. Myers, "Osseointegration in skeletal reconstruction and rehabilitation: A review." Journal of Rehabilitation Research and Development, vol. 38, no. 2, pp. 175-181, 2001.

[16] D. Taylor, "Fracture and repair of bone: A multiscale problem.” J. Mater. Sci., vol. 42, no. 21, pp. 8911-8918, 2007.

[17] K. Engel, R. Herpers, and U. Hartmann, "Biomechanical Computer Models.” Elsevier, 2011.

[18] W. Maurel, D. Thalmann, Y. Wu, and N. M. Thalmann, Biomechanical "Models for Soft Tissue Simulation.” Berlin, Heidelberg: Springer Berlin Heidelberg, 1998.

[19] R. W. Ogden, "Large deformation isotropic elasticity - On the correlation of theory and experiment for incompressible rubberlike solids.” Proceedings of the Royal Society of London. Series A, Mathematical and Physical Sciences, vol. 326, no. 1567, pp. 565-584, 1972.

[20] B. Calvo, E. Peña, M.A. Martínez, M. Doblaré, "An uncoupled directional damage model for fibered biological soft tissues. Formulation and computational aspects.” Int. J. Numer. Meth. Eng., vol. 69, pp. 2036-2057, 2007.

[21] J.E. Sanders, J.M. Greve, S.B. Mitchell, S.G. Zachariah, "Material properties of commonly-used interface materials and their static coefficient of friction with skin and socks.” J. Rehab. Res. Dev., vol. 35, pp. 161-176, 1998.

[22] D. T. Reilly and A. H. Burstein, "The mechanical properties of cortical bone." J. Bone Jt. Surg., vol. 56, pp. 1001-1022, 2011.

[23] Kutzner, B. Heinlein, F. Graichen, A. Bender, A. Rohlmann, A. Halder, A. Beier, and G. Bergmann, "Loading of the knee joint during activities of daily living measured in vivo in five subjects.” J. Biomech., vol. 43, no. 11, pp. 2164-2173, 2010.

[24] D. R. Carter and W. C. Hayes, "Bone compressive strength: the influence of density and strain rate.” Science, vol. 194, no. 4270, pp. 1174-1176, 1976.

[25] H. Weinans, R. Huiskes, H.J. Grootenboer, "The behavior of adaptive boneremodeling simulation models.” J. Biomech., vol. 25, no. 12, pp. 1425-1441, 1992.

[26] S. Portnoy, Z. Yizhar, N. Shabshin, Y. Itzchak, A. Kristal, Y. Dotan-Marom, I. SievNer, A. Gefen, "Internal mechanical conditions in the soft tissues of residual limb of a trans-tibial amputee.” J. Biomech., vol. 41, pp. 1897-1909, 2008. 